\title{
CONCEPÇÕES ATRIBUÍDAS POR MULHERES AO PROCESSO DE ADOECIMENTO POR LÚPUS
}

\author{
Hélida Vieira Xavier ${ }^{1}$ \\ Susane Vasconcelos Zanotti \\ Maria Auxiliadora Teixeira Ribeiro \\ Universidade Federal de Alagoas, Maceió- AL, Brasil.
}

\begin{abstract}
RESUMO. Este estudo busca compreender as concepções atribuídas por algumas mulheres ao processo de adoecimento por Lúpus Eritematoso Sistêmico (LES). Foram entrevistadas nove mulheres que realizaram tratamento no ambulatório de reumatologia de um hospital universitário do Nordeste Brasileiro. Os dados obtidos foram organizados, a partir da análise de conteúdo, em cinco temas-eixo: O início da doença; Corpo e lúpus; O tratamento; Lúpus e suas causas; e Discurso médico e o Lúpus. Para interpretação dos dados foi utilizada a teoria psicanalítica, especialmente as concepções de corpo e adoecimento. Os resultados indicaram que o adoecimento por Lúpus promove estranhamento, acometendo o corpo e sua imagem e causando angústia. Não obstante, com o decorrer do tratamento essas mulheres passaram a se reconhecer na condição de doente crônico. Tal condição é compreendida por elas a partir de referenciais simbólicos do discurso médico que auxiliam na constituição de uma nova imagem corporal e provocam modificações nos modos de vida.
\end{abstract}

Palavras-chave: Distúrbios imunológicos; mulheres; psicanálise.

\section{CONCEPTIONS ATTRIBUTED BY THE WOMEN TO THE DISEASE PROCESS FOR LUPUS}

\begin{abstract}
This study aims to understand the concepts attributed by women to the disease process of Systemic Lupus Erythematosus (SLE). We have interviewed nine women who were undergoing treatment at the outpatient rheumatology clinic of a university hospital in the Northeast of Brazil. The collected data was organized, based on content analysis, in five axis: disease onset; body and Lupus; the treatment; Lupus and its causes; medical discourse and Lupus disease. As for interpreting the data, psychoanalytic theory was used with that aim, especially its conceptions of body and illness. Results indicated that the Lupus disease process leads to estrangement, affecting the body and its image and causing anguish. Nevertheless, with the course of treatment, these women began to recognize themselves in a condition of chronic patient. This condition is understood by them from the symbolic references provided by medical discourse which aids in the assemblage of a new body image and provokes changes in their lifestyles.
\end{abstract}

Keywords: Immunologic disorders; women; psychoanalysis.

\section{CONCEPCIONES ATRIBUIDOS POR MUJERES AL PROCESO DE LA ENFERMEDAD POR LUPUS}

RESUMEN. Este estudio busca comprender los conceptos atribuidos por las mujeres, al proceso de la enfermedad de Lupus Eritematoso Sistémico (LES). Fueron entrevistadas nueve mujeres que realizaban tratamiento en un ambulatorio de reumatología de un Hospital Universitario en el noreste brasileño. Los datos fueron organizados a partir del análisis de contenido, en cinco temas-ejes: El principio de la enfermedad; Cuerpo y Lupus; El tratamento; Lupus y sus causas y; El discurso médico y el Lupus. Para interpretar de los datos fue utilizada la teoría psicoanalítica, especialmente las concepciones del cuerpo y la enfermedad. Los resultados indicaron que la enfermedad por Lupus promueve lo estrañamiento, que afecta el cuerpo y su imagen y que causa angustia. Sin embargo, con el transcurso del tratamiento, estas mujeres comenzaron a reconocerse en una condición de enfermo crónico. Tal condición es entendida por ellas a través de las referencias simbólicas del discurso médico, que ayudan en la formación de una nueva imagen corporal y provoca cambios en los estilos de vida.

\footnotetext{
${ }^{1}$ Endereço para correspondência: Av. Maceió, 50, Tabuleiro dos Martins - CEP 57061-110 - Maceió-AL, Brasil.. E-mail: helida.x@gmail.com.
} 
Palabras-clave: Transtornos inmunologicos; mujeres; psicoanálisis.

O interesse pelo tema do adoecimento por lúpus, uma patologia autoimune, surgiu a partir da prática clínica da autora supervisionada pelas coautoras, vinculada ao Programa de Residência Integrada Multiprofissional em Saúde, no Serviço de Reumatologia de um hospital universitário no Nordeste do Brasil, no Programa de Residência Integrada Multiprofissional em Saúde. No primeiro momento de trabalho no hospital houve o acompanhamento de um grupo de apoio direcionado a pacientes acometidos por patologias reumatológicas. Foram realizadas atividades de caráter multiprofissional, com o objetivo de proporcionar aos pacientes atendidos no ambulatório um espaço de fala para a expressão de sua experiência de adoecimento. No segundo momento, uma equipe multiprofissional, composta por médico, psicólogo, fisioterapeuta, nutricionista e farmacêutico, desenvolveu atividades direcionadas aos pacientes participantes ou não do grupo de apoio.

Tanto as atividades ambulatoriais quanto o trabalho realizado junto ao grupo de apoio despertaram o interesse em analisar as narrativas singulares dos pacientes sobre seu adoecer e tratamento. Assim, foi realizada a pesquisa "Nomes do Lúpus: construindo roteiros adaptados", com o objetivo de conhecer a história que sujeitos acometidos por Lúpus Eritematoso Sistêmico (LES) constroem sobre seu adoecer, apontando sentidos, causalidades e efeitos, ou seja, sua posição subjetiva em relação ao que padecem. A pesquisa objetivou ainda conhecer a concepção sobre o tratamento de lúpus de cada paciente e identificar a posição adjudicada ao médico do ambulatório de reumatologia em relação ao tratamento.

\section{Lúpus Eritematoso Sistêmico}

De acordo com a Sociedade Brasileira de Reumatologia (SBR), o lúpus é uma doença de natureza autoimune que produz inflamação crônica e acomete vários órgãos e sistemas (Sato et al., 2008). Sua etiologia permanece parcialmente desconhecida, mas o desenvolvimento da doença é ocasionado por múltiplos fatores, entre eles a interação de elementos genéticos com fatores ambientais, medicamentosos e infecciosos (Sato, 2008). A evolução do lúpus apresenta manifestações clínicas multiformes com fases exacerbadas e períodos de remissões. Como destaca Andrade (2009), apesar do considerável progresso científico de diferentes áreas da saúde, o tratamento do lúpus ainda apresenta desafios, por abranger condições que variam de formas brandas até condições rapidamente fatais.

Essa patologia é rara e acomete frequentemente mulheres de idade entre 15 e 65 anos, numa proporção de nove a dez mulheres para cada homem afetado, independentemente da raça (Sato, 2008). De acordo com Sato (2008), numerosos estudos acerca da incidência e prevalência de LES foram efetuados nos Estados Unidos, na Inglaterra e nos países nórdicos. Em termos epidemiológicos, nas últimas décadas a incidência da doença tem alternado de 3,7 a 5,5/100.000 habitantes, já a prevalência varia de 14,6 a 50,8 casos $/ 100.000$ habitantes (Sato, 2008).

Segundo a SBR (2012), no Brasil não se dispõe de dados exatos, mas as estimativas indicam a existência de aproximadamente 65.000 indivíduos com lúpus, que são predominantemente mulheres, o que significa dizer que uma de cada 1.700 brasileiras tem LES. Como contrário à incerteza descrita acerca da indisposição de dados epidemiológicos no Brasil destaca-se um estudo realizado em 2000 na cidade de Natal (RN), que aponta uma incidência de 8,7/100.000 habitantes, uma taxa elevada, se comparada à observada em outras regiões do mundo (Vilar, Rodrigues \& Sato, 2003).

As manifestações clínicas dessa doença podem ser genéricas e/ou específicas, a depender do órgão ou sistema comprometido. Entre as primeiras figuram manifestações que Sato (2008) destaca como queixas constitucionais, as quais são comumente observadas no período de atividade da doença, como febre, emagrecimento, fraqueza, perda de apetite e desânimo. Entre as específicas, a depender do órgão, estão a artrite, serosites, lesões mucosas, lesões cutâneas, comprometimento renal, neurológico, pulmonar, cardíaco e hematológico, vasculite e outras (Sato, 2008).

O lúpus caracteriza-se por ser de difícil diagnóstico, seja devido ao polimorfismo das manifestações clínicas da doença seja pela ausência de signo patognomônico e falta de exame laboratorial específico. Para conclusão diagnóstica do LES empregam-se os critérios de classificação 
propostos em 1982 pelo Colégio Americano de Reumatologia e revisados em 1997 por Hochberg (Sato et al., 2008). Fundamenta o diagnóstico a presença de pelo menos quatro dos onze critérios, que são: eritema malar, lesão discoide, fotossensibilidade, úlceras orais/nasais, artrite, serosite (pleuris ou pericardite), comprometimento renal, alterações neurológicas (convulsão ou psicose), alterações hematológicas como leucopenia, linfopenia, plaquetopenia e anemia hemolítica, alterações imunológicas e anticorpos antinucleares, como o anticorpo anti-DNA nativo ou anti-Sm ou presença de anticorpo antifosfolípede (Sato et al., 2008).

Por ser uma doença do sistema imunológico, o lúpus se caracteriza pela produção de vários autoanticorpos patogênicos e imunocomplexos. Estes autoanticorpos reagem com proteínas do organismo, causando inflamações em diversos órgãos e sistemas. Desta maneira, a pessoa que tem LES pode apresentar diferentes tipos de sintomas e em diversas partes do corpo (SBR, 2012).

A importância da relação do sujeito com o seu próprio corpo, quando com lúpus, foi mencionada em estudo comparativo realizado por Pinheiro et al. (2006) entre mulheres acometidas por lúpus e mulheres melancólicas. As autoras constataram, no referido estudo, que o primeiro grupo apresentou peculiaridades quanto à relação que estabelecem com seu corpo que dizem respeito à unificação frágil, vacilante e precariamente estabilizada da própria imagem corporal, circunstância geradora de acentuada angústia (Pinheiro et al., 2006).

A singularidade com que os sintomas se desenvolvem está subordinada ao tipo de anticorpo apresentado por um indivíduo e ao modo como a evolução deste anticorpo interage com as características genéticas de tal indivíduo. Em outras palavras, cada sujeito com lúpus tende a apresentar sintomatologia particular e pessoal (SBR, 2012). Entendemos que a perspectiva de consideração do particular do discurso pode se mostrar consubstancial no acompanhamento terapêutico multiprofissional de sujeito com lúpus. Isto se deve às novas formas de sofrimento psíquico, transformações nas demandas e manifestações sintomáticas das quais o corpo se torna palco - como as adições, distúrbios alimentares, automutilação, dores. Tais modificações convocam psicólogos e psicanalistas, que exercem suas atividades em ambulatórios públicos de saúde, à constante formalização da prática clínica (Besset, Zanotti et al., 2010).

Como enfatizam os supracitados autores, a prática clínica no campo da saúde exige de nós, psicólogos, fidelidade aos princípios que orientam a clínica e atenção às subjetividades do tempo atual (Besset, Zanotti et al., 2010). Tal esforço se faz salutar no tocante à prática do psicólogo inserido em equipe multiprofissional de saúde.

\section{MÉTODO}

Para empreender a pesquisa realizou-se uma revisão bibliográfica alicerçada no aporte teórico psicanalítico, especificamente nas teorias de Freud, Lacan e seus comentadores contemporâneos que abordam as temáticas da pesquisa. Concomitante ao estudo teórico, entrevistou-se nove mulheres com idades entre 21 e 38 anos, acometidas por lúpus e em tratamento no referido ambulatório.

Para a revisão bibliográfica empreendemos uma busca em bibliotecas virtuais (BVS Psi, Scielo, Bireme, Periódicos Capes) com a combinação dos seguintes descritores "psicanálise", "lúpus eritematoso sistêmico", "doença autoimune", "corpo", "angústia". Como resultado, deparamo-nos com artigos oriundos de apenas uma pesquisa de base psicanalítica sobre o lúpus, o que evidencia a carência de estudos no campo da psicanálise acerca desta patologia autoimune.

Para identificar os possíveis participantes da pesquisa foi utilizado o grupo de apoio e, através dele, efetuado o convite. Nesse ínterim, uma das pesquisadoras apresentou a pesquisa, seus objetivos, o método, e por fim convidou mulheres maiores de 18 anos com lúpus a participarem da pesquisa. Cabe ressaltar que as nove entrevistadas não estavam em acompanhamento psicológico no ambulatório de reumatologia, mas após a entrevista algumas delas solicitaram acompanhamento psicoterápico ambulatorial.

Por se tratar de uma pesquisa com seres humanos, as nove mulheres que se dispuseram a participar assinaram o Termo de Consentimento Livre e Esclarecido (TCLE). O projeto foi avaliado e aprovado pelo comitê de ética da universidade em que a pesquisa foi realizada (processo $n^{\circ}$ 012488/2011-20).

No tocante à pesquisa de campo, este trabalho priorizou uma metodologia qualitativa, tendo como meio de informação entrevistas semiestruturadas (Minayo, 2011). Foi elaborado pelas pesquisadoras um roteiro com treze perguntas, conciliando a 
objetividade das questões que almejamos abordar no campo e a contingência que este tipo de pesquisa suscita. Segundo Minayo (2011), o roteiro de entrevista é um instrumento de orientação, um guia que "serve de baliza para o pesquisador e não de cerceamento da fala dos entrevistados" (p. 122). A resposta das participantes às perguntas do roteiro provocou a formulação de outras questões não antecipadas, as quais dizem respeito ao discurso de cada participante sobre os temas da pesquisa. Neste contexto de coleta de dados em campo o imprevisível não foi recusado. Assim, a fala das participantes fomentou a elasticidade do roteiro e estas foram convidadas a falar mais sobre questões referentes a temas abordados na pesquisa.

O roteiro de entrevista abordou as condições das entrevistadas desde o início de seu adoecer até a entrada em tratamento no Serviço de Reumatologia. Além disso, intentou conhecer como a entrevistada concebe seu tratamento, como descreve a relação estabelecida com o médico reumatologista responsável por seu tratamento e como a participante define sua patologia, e possível associação entre $o$ seu adoecer e os acontecimentos específicos em sua vida.

As entrevistas foram gravadas e posteriormente transcritas. Seu conteúdo foi organizado por meio da técnica da análise de conteúdo (Bardin, 2009). O emprego desta técnica teve por intuito sistematizar o material apresentado pelas entrevistadas, mediante a definição de categorias que ordenassem os dados e possibilitassem alcançar os objetivos propostos. As respostas foram organizadas sob a forma de cinco temas-eixo: "O início da doença", "Corpo e lúpus" "O tratamento", "Lúpus e suas causas" e "Discurso médico e o Lúpus". A partir desses eixos foi efetivada a análise de conteúdo.

\section{RESULTADOS E DISCUSSÃO}

Ao serem convidadas a falar sobre o processo de adoecimento - como definem o lúpus -, sobre os acontecimentos de sua vida do período em que desenvolveram a doença e sobre o presente, as entrevistadas iniciaram a fala com situações que remontavam ao período anterior à evolução da doença. Em seguida, descreveram as primeiras manifestações sintomáticas, a variedade de especialistas consultados e os tratamentos empreendidos por estes.
As participantes relataram suas experiências subjetivas subjacentes ao processo de adoecimento, suas possíveis causas e perspectivas quanto ao tratamento ao qual estavam se submetendo, haviam se submetido ou poderiam vir a submeter-se. Por fim, discorreram sobre a relação estabelecida com a reumatologista que as acompanha.

\section{O início da doença}

Para a maioria das entrevistadas, falar de seu adoecer inclui o período anterior ao da aparição dos primeiros sintomas. De acordo com elas, o préadoecimento foi caracterizado por dificuldades e conflitos nos âmbitos familiar, laboral e escolar, ou marcado pela vivência de intensa angústia, advinda de uma separação ou da morte de uma pessoa estimada. Ainda foram recorrentes falas sobre mudanças de domicílio, cidade, estilo de vida, estado civil e sobre períodos de maturação humana (puberdade) e gravidez (desempenho da função materna). Supõe-se, dessa maneira, que os elementos comuns de aflição na fala das entrevistadas indiquem a existência de algo que era fonte de angústia muito antes de adoecerem.

Chama também a atenção o fato de que, para algumas entrevistadas, o lúpus emerge diante da irrupção do real da puberdade. Segundo Stevens (2004), o real ${ }^{2}$ da puberdade não são, pura e simplesmente, transformações do corpo, mas o que emerge com tais transformações: a não relação sexual faz vacilar as palavras. A partir da teoria lacaniana, Stevens (2004) esclarece que "isso quer dizer que não há uma relação no sentido matemático, no sentido de um saber instituído e constituído, já presente, sobre o que é a relação entre um homem e uma mulher" (p. 35). A não relação sexual se dá, pois, na falta de saber a priori sobre aquilo que complementa os sexos (Stevens, 2004).

Segundo Freud (1895/1996), o encontro sexual é traumático para qualquer sujeito, pois a assimilação simbólica da sexualidade é complexa. Independentemente da oferta de um saber sobre os corpos que estão em transformação, este reencontro com os traumas sexuais infantis que vêm à cena durante a puberdade serão sempre traumáticos para os jovens. É neste contexto do

\footnotetext{
${ }^{2}$ O Real corresponde a um dos três registros conceituais lacanianos introduzidos em 1953. Em linhas gerais, o registro do Real se caracteriza como o que resiste a ser simbolizado (Lacan, 1963-1964/1985).
} 
encontro com o real da não relação sexual na puberdade pela falta de significantes para nomear o que acontece a seus corpos que o jovem cria saídas para o mal-estar inassimilável que o acomete. Nesse contexto, o adoecer poderia ser uma destas saídas possíveis.

Para outras entrevistadas, o adoecer é precedido pelo luto de perdas, como a separação do cônjuge ou dos pais ou pela morte de entes queridos, situações de conflito que evocam, assim como na puberdade, algo de traumático para essas mulheres e acontecimentos para os quais $o$ ato de nomeação, ou seja, a criação de sentidos, estava limitado pela ausência de significantes que pudessem elaborar o que thes ocorria ou criar saídas menos angustiantes para tais acontecimentos traumáticos que as afligiam. Destarte, perante o encontro traumático com o real da sexualidade emergente na puberdade ou diante do real da perda, o adoecer poderia ser uma resposta física ao encontro angustiante, "uma saída plausível perante a ameaça de ruptura do psiquismo trazida pela vivência do trauma" (Fonseca, 2007, p. 235).

A angústia que mobilizara o fenômeno do adoecer nestes moldes descritos acima sugere tratar-se de uma manifestação do real como aquilo que escapa "às leis da linguagem, não sendo traduzido em palavras e se manifestando como uma mostração no corpo" (Fonseca, 2007, p. 232). Nesta perspectiva, o adoecimento por lúpus poderia ilustrar um fenômeno psicossomático que é da ordem do real e não está sujeito a qualquer decifração, diferindo da noção de causalidade que subjaz ao sintoma - este inscrito na dimensão da metáfora (Fonseca, 2007). Sendo assim, as entrevistadas se encontravam subjetivamente excluídas e alheias ao que lhes ocorria no corpo psíquica e corporalmente, pois o sujeito está impossibilitado de se apropriar do que lhe advém em meio ao trauma, não se implicando em sua ocorrência (Fonseca, 2007).

As entrevistadas descreveram que com a irrupção dos primeiros sintomas começou a peregrinação por diversos especialistas da área médica - dermatologistas, infectologistas, endocrinologistas, hematologistas - na busca de respostas para seu sofrimento corporal. Conforme ressaltamos anteriormente, no que concerne ao LES o diagnóstico não é simples, amiúde é instituído após consulta a profissionais de variadas especialidades.
A maioria das participantes teve dificuldades em receber uma conclusão diagnóstica de lúpus, cuja investigação chegou a atravessar anos. Algumas receberam diagnósticos incorretos, iniciando tratamentos inapropriados que apenas apaziguavam os sinais clínicos, quando não provocavam lesões iatrogênicas. Este último ponto pode ser verificado no relato de uma das entrevistadas: "Fui primeiro para a dermatologista daqui, quem me encaminhou pra cá foi a infectologista, porque eu estava tomando a medicação errada, me deram diagnóstico de hanseníase e eu só estava piorando".

O diagnóstico de lúpus causou um impacto em suas vidas e o sofrimento emergiu com a notícia, conforme mencionou outra participante: "Comecei a chorar desesperada, disseram que não podia ter filho e isso me assustou. Não queria aceitar de jeito nenhum, antes minha vida era ativa, de repente, por causa do tratamento, eu ia deixar tudo de lado pra me cuidar". Esse relato expõe a dimensão impactante do diagnóstico na vida da entrevistada, a quem as mudanças esperadas com o tratamento causaram temor.

\section{Corpo e lúpus}

No momento em que o corpo anuncia sua existência por meio do adoecer, entra em cena o mal-estar, queixa constante ouvida nos depoimentos das pacientes entrevistadas. "Enquanto o homem não lembra dos seus órgãos, vai tudo bem para ele, mas quando o órgão dá sinais que chamam a atenção, eis o impacto, a estranheza, a angústia" (Moretto, 2007, p. 123).

Como se pode observar nos depoimentos acima transcritos, com o diagnóstico de lúpus as entrevistadas se depararam "se esbarra com o incontrolável e com a fragilidade da condição humana. Então o sujeito humano, que é incompleto, ao adoecer tem sua fragilidade exposta para si e para o outro também" (Moura, 2003, pp. 17-18). Instaura-se, assim, um momento de contingências para o sujeito doente, em que desaparece o previsível outrora reinante. Em outras palavras, o familiar do corpo passa a dar lugar ao horror do estranho da doença, algo estranho que habita aquele que sofre com o impacto de manifestações sintomáticas que desvelam o corpo real carente de representação simbólica e de palavras para conter o inassimilável do fenômeno do adoecer.

Dito isto, podemos considerar o adoecimento por lúpus como um acontecimento que afeta o 
corpo e causa estranhamento ao sujeito, reflexão que nos remete às considerações de Freud (1919/1996) em seu texto $O$ estranho. Segundo o autor: o encontro com aquilo que causa estranheza (unheimlich) suscita horror, acarretando uma vacilação despersonalizante. Em outras palavras, o desconhecimento de si perante a imagem corporal afetada pelos sinais clínicos do lúpus (eritema malar, lesão discoide e alopecia, por exemplo) causa estranhamento e horror às participantes. Assim, o que irrompe da imagem corporal de si mesmo no momento em que o estranho vem à tona é a angústia. Por isso, conforme ressalta Lacan (1962-1963/2005) no Seminário $X$, este sentimento de estranheza "é a porta aberta para a angústia" (p. 100).

A estranheza e a angústia emergentes no processo de adoecer por envolver modificações na imagem corporal, foram evidenciadas na fala de uma jovem entrevistada: "Tenho dificuldade em relação às manchas. Eu evito ir à praia porque eu sinto muita vergonha. Até no meu relacionamento tenho vergonha das manchas, é horrível! Essas manchas mexeram totalmente comigo, mexeram não, mexem totalmente comigo, me causa muita angústia”. Para esta participante, o reconhecimento de seu corpo marcado por manchas se dá com intensa angústia e vergonha.

$\mathrm{Na}$ análise das entrevistas foi possível ainda constatar o estranhamento das participantes diante do diagnóstico de lúpus. Este dado denotou que o reconhecimento da condição de doente crônico não se dá sem entraves. Semelhante a esta colocação, apresentamos o recorte da entrevista de uma participante: "Por mais que a gente aceite, sempre fica aquela questão de doença crônica. Não é que você esqueça, não é possível esquecer uma doença dessas, às vezes passa despercebido da vida, mas quando a gente lembra dá uma angústia forte". Este relato evidencia que, para esta mulher, a assunção subjetiva de uma nova imagem corporal - marcada pelo significante referente à cronicidade da doença - não é um ato de assimilação sem sofrimento.

\section{O tratamento}

As pacientes procuram o serviço do ambulatório seja por demanda espontânea, apresentando manifestações clínicas gerais e/ou específicas, seja por encaminhamento de outros médicos que suspeitam do diagnóstico de lúpus. Realizada a consulta médica, como conduta geral para investigação diagnóstica o reumatologista solicita o internamento hospitalar da paciente. Tão logo concluído o período de investigação e confirmado o diagnóstico de lúpus a paciente inicia seu tratamento medicamentoso, que dependerá dos órgãos ou sistemas acometidos e da gravidade da doença.

Além do atendimento médico tradicional, o tratamento de pacientes com lúpus no serviço onde a pesquisa foi realizada dispõe de outros dois dispositivos: o grupo de apoio e o atendimento ambulatorial multiprofissional. O grupo de apoio apresenta histórico de cerca de treze anos e foi criado mediante uma parceria entre uma médica reumatologista e uma das coautoras deste trabalho. Na época a médica reumatologista notou nos pacientes com artrite reumatoide certa dificuldade em aderir ao tratamento e propusera uma parceria com a docente de Psicologia da universidade para elaboração de atividades em grupo com tais pacientes. Dois objetivos pautaram estes encontros: proporcionar a estes indivíduos um espaço de fala para a expressão livre de sua experiência de adoecimento e elevar a taxa de adesão ao tratamento indicado pela reumatologista. Como o grupo foi bem-sucedido em ambas as propostas, as coordenadoras das atividades abriram vagas para sujeitos com outros diagnósticos de colagenoses que não somente artrite reumatoide, inclusive os pacientes com lúpus.

Para participar do grupo é necessário o convite do reumatologista feito no ambulatório por ocasião de consulta médica. O convite se caracteriza por um chamado à verbalização de experiências de vida, do sofrimento exposto no espaço do ambulatório, e à socialização. Em geral, após duas ou três consultas médicas os pacientes são chamados a participar dos encontros. Comumente, o convite é feito a todos aqueles que são atendidos no ambulatório e o nível de assiduidade aos encontros mensais gira em torno de trinta pessoas. Quanto ao atendimento individual, este teve início em 2011, com o início das atividades ambulatoriais da Residência Multiprofissional Integrada em Saúde, e conta com um farmacêutico, um fisioterapeuta, um nutricionista e um psicólogo.

$\mathrm{O}$ atendimento multiprofissional em casos de lúpus justifica-se pelos aspectos abarcados no tratamento desse tipo de doença autoimune. Entre aqueles mencionados em artigos das diferentes áreas envolvidas no tratamento, destacam-se: a influência de fatores nutricionais sobre as manifestações da doença (Klack, Bonfá \& Borba, 
2012); o incentivo do controle do peso como um dos principais objetivos do tratamento de todo paciente com LES (Santos, Borges, Correia, Telles \& Lanna, 2010); a intervenção psicológica como importante ferramenta no tratamento do LES (Cal, 2011); e os aspectos relacionados à sexualidade, em casos de adolescentes com lúpus (Silva et al., 2009).

Apesar das estratégias de tratamento utilizadas no serviço de reumatologia onde a pesquisa foi realizada, a maneira como cada sujeito reage ao diagnóstico está essencialmente associada à sua subjetividade (Moretto, 2007). Ao considerarmos o peso da historicidade de quem adoece na forma como este se relaciona com sua doença, podemos dizer que, para as participantes, o início do adoecer e do tratamento foi marcado por um sofrimento que afetou seu corpo com marcas definitivas, pelo escamoteamento das orientações médicas, pela dificuldade em assimilar $o$ presente e pelo questionamento sobre o futuro.

Não obstante, com o decorrer do tratamento medicamentoso e da participação nas atividades do grupo de apoio, as participantes passaram a estabelecer outra relação com sua doença. Tais mulheres migraram do estranhamento causado pelo adoecimento por lúpus e da carga de angústia advinda daí, para o reconhecimento do adoecer e da construção de nova imagem corporal. Começaram a apresentar modificações no estilo de vida em busca de uma condição de saúde mais estável, como podemos constatar no relato de uma entrevistada: "No início parece difícil, a gente sente que fisicamente e emocionalmente é difícil, mas depois vai passando, vai melhorando, vai suavizando, e não é aquele bicho de sete cabeças. Hoje eu estou bem". Outra participante ressalta a transição de um período ao outro: "No começo é muito difícil, eu não sabia que estava acontecendo comigo, com meu corpo. Mas hoje não é tão difícil, durmo bem, me alimento bem, tomo a medicação. Os sintomas, tanto emocionais quanto físicos, melhoraram".

Diante dessas respostas foi possível verificar que os resultados das entrevistas estão em consonância com a afirmação de Moretto (2007) quando ressalta que de início o sujeito denega sua doença, "e isso explica muitas vezes a dificuldade que tem de assumir-se nesta posição de doente e tratar de sua doença, responsabilizar-se por um tratamento médico que termina tendo sua eficácia comprometida" (Moretto, 2007, p. 124).

Para a autora, apenas num segundo momento é possível ao sujeito entender sua doença como aspecto integrante da sua identidade, culminando num posicionamento ativo quanto ao tratamento de sua doença. Ressalta ainda que esse ato de aceitação não está subordinado à argumentação lógica e racional. Por fim, Moretto (2007) adverte que admitir condutas médicas e engajar-se no tratamento sem resistência pode indicar também a identificação do sujeito ao objeto doença. Isso demandaria cuidados intensivos e atenção familiar que de outra maneira talvez não se obtivessem exceto neste lugar e nestas condições.

De acordo com algumas entrevistadas, o reconhecimento desta nova condição (doente crônico, corpo marcado por manchas, uso de medicações regulares e essenciais) demanda tempo, um tempo menos cronológico que subjetivo. Neste, a conjugação do espaço de escuta clínica, aberta ao advir da subjetividade das pacientes no âmbito do ambulatório e do espaço de expressão livre de suas narrativas pessoais no grupo de apoio, configura esses espaços como fecundos ao estabelecimento de laços transferenciais.

Pode-se considerar que algumas entrevistadas atravessaram as dificuldades descritas anteriormente, inerentes ao adoecimento, porque tiveram à disposição recursos simbólicos concedidos pelo médico, colegas de grupo e familiares que promoveram a reconstituição de uma nova imagem corporal, suporte de uma identidade (Pinheiro et al., 2006). A reestruturação da subjetividade nestas condições tende a causar menos angústia a tais mulheres à medida que são escutadas naquilo que as aflige e que, até então, permanecera sem sentido.

Assim, podemos identificar que a constituição de uma narrativa própria sobre o adoecer se dá por duas vias: a partir do saber que adquirem nas consultas médicas, na interpretação dos exames, nas pesquisas efetuadas na internet, que que constituem um "eixo identificatório" em torno do qual se constituem narcisicamente (Pinheiro et al., 2006, p. 199), e no âmbito do grupo de apoio por meio do estabelecimento de laços sociais. Ambas as etapas compõem uma matriz simbólica que dá contorno à unidade corporal do sujeito, assim como o arranjo imprescindível à criação de uma ficção própria (Pinheiro et al., 2006).

\section{Lúpus e suas causas}

Para conhecer e compreender a forma como as entrevistadas concebiam a progressão de seu adoecer, no decorrer das entrevistas investigamos a associação do adoecer a algum possível 
acontecimento por elas experienciado. As participantes elencaram possíveis causas desencadeantes de seu adoecer. Pelas respostas foi possível verificar que o lúpus irrompeu intimamente associado a fatores psíquicos como conflitos da esfera familiar, situações de estresse no trabalho e a vivência de angústia pela morte de alguma figura parental e/ou fraterna. Isto significa que na raiz do adoecer tais mulheres localizaram afetos e emoções que se configuraram como uma espécie de estopim do lúpus.

Costa (1989) expõe reflexões acerca da representação de "doença dos nervos" por sujeitos arrebatados por sofrimentos psíquicos. Quando convidado a falar sobre a etiologia do que o incomodava, o indivíduo adoentado reordenava "fragmentos de saberes, apropriados nas situações práticas de vida, e fornecia um arranjo explicativo" para o mal que o acometia (Costa, 1989, p. 20). A respeito do exposto acima sobre 0 ato de nomeação do sofrimento psíquico, o estudo de Costa (1989) nos ajuda a refletir acerca da elaboração de um discurso próprio do sujeito sobre seu adoecimento, mesmo que este não disponha de um saber científico. Igualmente, ajuda-nos a refletir sobre as representações de causalidade relatadas pelas participantes, representações que indissociáveis da subjetividade que as produz.

Transbordando de angústia em vários aspectos da vida antes e em decorrência do adoecer, sem compreenderem o que lhes acontecia, a doença parece advir para as entrevistadas como uma solução subjetiva para o mal-estar psíquico. Este fato é semelhante ao exposto por Besset, Gaspard, Doucet, Veras e Cohen (2010) acerca de um estudo sobre fibromialgia no qual o quadro característico da doença de dores difusas no corpo assume um papel na economia psíquica daqueles que dela sofrem. Os autores afirmam neste estudo, a partir de subsídios clínicos, que a fibromialgia tem uma função em relação à estrutura subjetiva de quem dela padece; ou, de outra forma, uma função que se assemelha a uma saída possível para o mal-estar ou, nas palavras dos autores, uma "solução subjetiva" (Besset, Gaspard et al., 2010, p. 1262).

Convém ressaltar que, mesmo reconhecendo o caráter enigmático na etiologia do lúpus (Sato et al., 2008), não há o reconhecimento da participação de fatores de ordem subjetiva na etiologia do lúpus. No capítulo "Verdades e mentiras sobre o lúpus eritematoso sistêmico" da Cartilha sobre o Lúpus da Sociedade Brasileira de Reumatologia (2012), o estresse emocional não se caracteriza como elemento causal da doença. Por outro lado, a partir de mecanismos desconhecidos, aventa-se a possível participação de emoções negativas (a exemplo do estresse, do luto ou de separações de casais) no desencadeamento dos sinais clínicos iniciais ou na reativação da doença, mas nunca como causa (Sato, 2008).

\section{Discurso médico e o lúpus}

Com a eclosão dos primeiros sintomas acompanhados de sofrimento físico e psíquico, o sujeito percebe a necessidade de consultar um médico. Suposto pelo sujeito doente como guardião de um saber sobre o corpo e o que the afeta, o clínico, de antemão, ocupa um lugar de saber no psiquismo daquele que Ihe solicita cuidados. $O$ endereçamento de uma demanda de cuidados está posta no momento mesmo do encontro entre o sujeito doente e o médico e seu saber. Deste modo, o que se deflagra neste encontro tangencia o estabelecimento de uma relação transferencial.

Como ressaltamos anteriormente, as participantes da pesquisa lançaram-se numa fatigante jornada por consultórios médicos, em busca da identificação da causa de seu padecimento. Algumas iniciaram tratamentos inadequados, que induziram ao agravamento dos sintomas; outras permaneceram sem assistência adequada por meses diante do furo que seu quadro clínico e a sintomatologia produziram no saber dos médicos que consultaram.

Entre a desconfiança na soberania do discurso médico e a dependência deste para obter respostas, cuidados e alívio, essas mulheres chegaram ao Serviço de Reumatologia do hospital em questão. Em face desta configuração turbulenta prévia e do estabelecimento de um laço transferencial que se desenvolve quando 0 paciente é atendido no serviço ambulatorial, intentamos identificar o lugar atribuído pelas entrevistadas à figura do médico reumatologista no que diz respeito ao tratamento proposto e perpetrado por este.

De acordo com o resultado das entrevistas, o reumatologista do ambulatório do hospital onde a pesquisa foi realizada assume a função de transmissor de um saber a partir das condutas, protocolos, orientações, recomendações, prescrições e encaminhamentos. Ao tocar, ver, falar, escrutinar o corpo, o especialista atribui o nome de lúpus eritematoso sistêmico ao mal-estar 
até então sem sentido, marcando de ali em diante uma nova fase da existência do sujeito. Nesses casos, uma narrativa peculiar do sujeito doente é construída a partir das queixas direcionadas ao discurso médico. Este confere ao sujeito doente atributos advindos do saber científico referentes à patologia lúpica. A paciente, por sua vez, apropriase de tais atributos e arquiteta uma nova imagem corporal, com a qual tende a se identificar (Pinheiro \& Herzog, 2003). "O discurso médico sobre o corpo doente funciona nesses casos como a apropriação de um vocabulário por meio do qual essas pacientes podem falar de si" (Pinheiro et al., 2006, p. 198).

Munidas deste arsenal simbólico projetado e introjetado, as pacientes acometidas pelo lúpus passaram a falar de si contemplando sintomas, diagnósticos, medicações, internações, complicações do quadro clínico, melhoras e inclusive a etiologia de ordem subjetiva fundada no particular de cada caso. Neste contexto, podemos verificar que, com a explicitação da paciente sobre acontecimentos traumáticos anteriores aos sintomas é construída uma série de causas que explicam o surgimento da doença, que é de caráter psicossomático Em outras palavras, a paciente expõe no âmbito do consultório a vivência de alguma situação traumática, como a morte de um familiar, e esta situação - somada a outras de ordem orgânica e ambiental - é assentida pelo crivo médico como propícia ao desencadeamento da doença. É neste sentido que uma das causas atribuídas como estopim do processo de adoecimento foram fatores psíquicos; e mesmo as causas de ordem mais objetiva, como a exposição em demasia à luz solar, decorrem de que o discurso médico as estabelece como possível fator de deflagração da doença.

Outro aspecto observado na pesquisa, decorrente dessa "filiação ao discurso médico", concerne ao fato de que o hospital frequentado pelas entrevistadas funciona como laço social, possibilitando o desenvolvimento de uma "noção de pertencimento" (Pinheiro et al., 2006, p. 199). Característica semelhante é discutida por Pinheiro e Vilhena (2007) ao discorrer sobre a dinâmica transferencial instituída em âmbitos institucionais: espaço que conjuga permanência e transitoriedade, "o hospital se apresenta como o lugar estável e seguro onde os pacientes são acolhidos quando e sempre que precisarem" ( $p$. 211). Desta forma, "oferece a confiança necessária para a instalação do campo transferencial" (Pinheiro \& Vilhena, 2007, p. 211).

Nos espaços do ambulatório e no grupo de apoio a existência destas mulheres é atestada e confirmada quando são convidadas a falar de suas dores, inclusive angústias, conflitos, reflexões, impasses e prazeres. As idiossincrasias são acolhidas, as subjetividades não são silenciadas, e desta forma se permite o advento de um espaço narrativo no qual o sujeito manifesta a realidade subjetiva de seu padecimento, visando a uma singularidade no delineamento de coordenadas próprias em sua vida (Besset, Gaspard et al., 2010).

\section{CONSIDERAÇÕES FINAIS}

Segundo Costa (1989), a doença existe segundo seu modo de expressão e foi este ato de expressão que quisemos observar no transcurso da pesquisa. Por meio da pesquisa foi possível constatar que o processo de adoecimento marcou e marca a vida das entrevistadas em sua existência e corpo de forma indelével, associando este adoecer a causas subjetivas prévias ao surgimento dos primeiros sintomas. Não sem sofrimento, elas assimilam a condição de doente crônico e suas limitações a elas impostas por essa condição, num processo atravessado por angústia, incertezas, perdas e dores.

Apesar de compartilharem de uma mesma patologia, das mesmas particularidades sintomatológicas e até do mesmo tratamento (medicação, posologia), a simbolização do lúpus para cada uma delas carrega o estatuto singular de uma enunciação, de uma articulação narrativa que acontece durante o relato de sua experiência de adoecimento. Ao consideramos a perspectiva do sujeito, entramos em contato com o delinear de uma teoria criada pelo indivíduo sobre 0 desenvolvimento da sua doença, com sentidos, emoções, afetos, etiologia e remissão ímpares.

Escutar a história dessas mulheres sobre o lúpus em suas vidas nos remete ao lugar que ele ocupa no discurso e estruturação subjetiva das entrevistadas. Por vezes, os papéis de protagonista e coadjuvante se alternam entre $o$ sujeito e a doença. Em geral, o lúpus assume um protagonismo na vida do sujeito, afetando, inclusive - como destacam Besset, Gaspard et al. (2010), a socialização e a economia psíquica de tais mulheres, impedindo a concentração em outras 
experiências de caráter afetivo ou social que não sejam relativas à doença.

Parece que, com o desencadeamento do lúpus, a vida passa a girar em torno da doença, das medicações, das orientações médicas e das limitações que ela impõe, dos exames e dos cuidados. Nas falas das entrevistadas sobra pouco ou nenhum espaço para o que quer que contrarie a arbitrariedade do papel que a doença assume em suas vidas. A posteriori, o protagonismo do sujeito sinaliza seu despontar com o engajamento no tratamento e a participação no grupo de apoio. Elas reconhecem a condição crônica da patologia e passam a apresentar outra relação com o lúpus, mediante a assunção de uma unidade corporal tangenciada por atributos advindos do saber médico. Outro aspecto favorável a uma mudança de posição quanto ao adoecimento se caracterizou pela união entre os espaços de fala e escuta oriundos do atendimento individual no ambulatório e os do grupo de apoio.

\section{REFERÊNCIAS}

Andrade, L. E. C. (2009). Future perspective for diagnosis in autoimmune diseases. Anais da Academia Brasileira de Ciências, 81(3), 367-380. Recuperado em 15 de Abril de 2013, de: http://www.scielo.br/pdf/aabc/v81n3/v81n3a04.pd f.

Bardin, L. (2009). Análise de conteúdo. Edição Revista e Actualizada Lisboa: Edições 70.

Besset, V. L., Gaspard, J.-L., Doucet, C., Veras, M., \& Cohen, R. H. P. (2010, dezembro) Um nome para dor: fibromialgia. Revista Mal-Estar e Subjetividade, 10 (4), 1243-1267. Recuperado em 08 de Março de 2013, de: http://pepsic.bvsalud.org/pdf/malestar/v10n4/09.p df.

Besset, V. L., Zanotti, S. V., Tenenbaum, D., Schimidt, N., Fischer, R., \& Figale, V. (2010, outubro/dezembro). Corpo e histeria: atualizações sobre a dor. Polêm!ca, 9 (4), 35-42. Recuperado em 08 de Março de 2013, de: http://www.polemica.uerj.br/ojs/index.php/polemic a/article/view/65/132.

Cal, S. F. L. de M. (2011). Revisão da literatura sobre a eficácia da intervenção psicológica no tratamento do lúpus eritematoso sistêmico. Psicologia: Teoria e Pesquisa, 27(4), 485-490. Recuperado em 15 de Abril de 2013, de: http://www.scielo.br/pdf/ptp/v27n4/12.pdf.

Costa, J. F. (1989). Psicanálise e contexto cultural: imaginário psicanalítico, grupos e psicoterapia. Rio de Janeiro: Campus.

Fonseca, M. C. B. (2007, julho/dezembro). Do trauma ao fenômeno psicossom0ático (FPS): lidar com o sem-sentido? Ágora, 10 (2), 229-244. Recuperado em 08 de Março de 2013, de: http://www.scielo.br/pdf/agora/v10n2/a06v10n2.p df.

Freud, S. (1996). Sobre o mecanismo psíquico dos fenômenos histéricos. In: J. Strachey (Ed., \& J. Salomão, Trad.) Edição Standard Brasileira das Obras Psicológicas Completas de Sigmund Freud (Vol. 2, pp. 39-53). Rio de Janeiro: Imago. (Obra original publicada em 1895).

Freud, S. (1996). O 'estranho'. In: J. Strachey (Ed., \& J. Salomão, Trad.) Edição Standard Brasileira das Obras Psicológicas Completas de Sigmund Freud (Vol. 17, pp. 235-273). Tradução de James Strachey. Rio de Janeiro: Imago. (Obra original publicada em 1919).

Klack, K., Bonfá, E., \& Borba, E. F., Neto. (2012). Dieta e aspectos nutricionais no lúpus eritematoso sistêmico. Revista Brasileira de Reumatologia, 52(3), 395-408. Recuperado em 15 de Abril de 2013, de: http://www.scielo.br/pdf/rbr/v52n3/v52n3a09.pdf.

Lacan, J. (1985). O Seminário, livro 11: os quatro conceitos fundamentais da psicanálise. (M.D. Magno, Trad.). Rio de Janeiro: Jorge Zahar Ed. (Obra original publicada em 1963-1964).

Lacan, J. (2005). O Seminário, livro 10: a angústia. (V. Ribeiro, Trad.). Rio de Janeiro: Jorge Zahar Ed. (Obra original publicada em 1962-1963).

Minayo, M. C. S. (2011). Pesquisa social: teoria, método e criatividade. (30ª ed.). Petrópolis: Vozes.

Moretto, M. L. T. (2007). O Outro em si: o transplante como risco e renascimento. In: J. Quayle, \& M. C. S. de Lucia. (Orgs.) Adoecer: as interações do doente com sua doença. (2a. ed., pp. 117-131). São Paulo: Editora Atheneu.

Moura, G. C. M. (2003). Urgência Subjetiva e Tempo: o que é isso? In: M. D. de Moura (Org.) Psicanálise e Hospital - 3. Tempo e morte: da urgência ao ato analítico. (pp. 17-21). Rio de Janeiro: Revinter.

Pinheiro, N. \& Vilhena, J. de. (2007). Entre o público e o privado: a clínica psicanalítica no ambulatório hospitalar. Arquivos Brasileiros de Psicologia, 59 (2), 201-216. Recuperado em 08 de Março de 2013 , de: http://seer.psicologia.ufrj.br/index.php/abp/article/ view/121/116.

Pinheiro, T. \& Herzog, R. (2003). Impasses na clínica psicanalítica: a invenção da subjetividade. Recuperado em 03 de Dezembro de 2011, de: http://egp.dreamhosters.com/encontros/mundial_ rj/download/5c_HerzogPin_142161003_port.pdf.

Pinheiro, T., Verztman, J., Venturini, C., Viana, D., Canosa, L. \& Caravelli, S. (2006). Patologias narcísicas e doenças auto-imunes: algumas considerações sobre o corpo na clínica. Psicologia Clínica, 18 (1), 193-204.

Santos, F. de M. M. dos, Borges, M. C., Correia, M. I. T. D., Telles, R. W., \& Lanna, C. C. D. (2010). 
Avaliação do estado nutricional e da atividade física em pacientes com lúpus eritematoso sistêmico. Revista Brasileira de Reumatologia, 50(6), 631-638. Recuperado em 15 de Abril de 2013, de: http://www.scielo.br/pdf/rbr/v50n6/v50n6a04.pdf.

Sato, E. I. (2008). Lúpus Eritematoso Sistêmico. In: J. C. Voltarelli (Org.). Imunologia Clínica na prática Médica. (Cap. 29, pp. 651-662). São Paulo: Atheneu.

Sato, E. I., Bonfá, E., Costallat, L. T. L., Pádua, P. M. de, Zimmermann, A. F., Silva, N. A. da, Kayser, C., Brenol, J. C. T., Latorre, L. C., \& Borba, E. F. (2008, julho/agosto). Consenso de Lúpus Eritematoso Sistêmico. Revista Brasileira de Reumatologia, 48 (4), 196-207. Recuperado em 03 de Fevereiro de 2012, de: http://www.scielo.br/pdf/rbr/v48n4/v48n4a02.pdf.

Silva, C. A. A. da, Febrônio, M. V, Bonfá, E., Pereira, R. M. R., Pereira, E. A. G. de., \& Takiuiti, A. D. (2009). Função sexual e saúde reprodutiva em mulheres adolescentes com lúpus eritematoso sistêmico juvenil. Revista Brasileira de Reumatologia, 49(6), 690-702. Recuperado em 15 de Abril de 2013, de: http://www.scielo.br/pdf/rbr/v49n6/v49n6a06.pdf.
Sociedade Brasileira de Reumatologia (2012). Lúpus Eritematoso Sistêmico (LES) - Cartilha da SBR. São Paulo: Autor. Recuperado em 19 de Fevereiro de 2012: http://www.reumatologia.com.br/mural/arquivos/L ES_Cartilha_PDF_COMPLETO_2011.pdf.

Stevens, A. (2004, novembro). Adolescência, sintoma da puberdade. Curinga, 20, 27-39.

Vilar, M. J. P., Rodrigues, J. M. \& Sato, E. I. (2003, novembro/dezembro). Incidência de Lúpus Eritematoso Sistêmico em Natal, RN - Brasil. Revista Brasileira de Reumatologia, 43 (6), 34751. Recuperado em 08 de Março de 2013, de: http://www.scielo.br/pdf/rbr/v43n6/a05v43n6.pdf..

Recebido em 18/04/2012 Aceito em 18/04/2013

Hélida Vieira da Silva Xavier: Psicóloga Residente. Hospital Universitário Prof. Alberto Antunes, Universidade Federal de Alagoas.

Susane Vasconcelos Zanotti: Docente/Tutora. Programa de Residência Multiprofissional em Saúde do Adulto e Idoso. Hospital Universitário Professor Alberto Antunes. Universidade Federal de Alagoas (UFAL).

Maria Auxiliadora Teixeira Ribeiro: Docente/Tutora. Programa de Residência Multiprofissional em Saúde do Adulto e Idoso. Hospital Universitário Professor Alberto Antunes. Universidade Federal de Alagoas (UFAL). 